\title{
Lessons Learned from Great East Japan Earthquake Disaster
}

\author{
-From Report on the Great East Japan Earthquake \\ Disaster; Mechanical Engineering Volume-
}

\author{
Japan Atomic Energy Agency, Yasuo Koizumi
}

\begin{abstract}
This commentary mainly discusses the recommendations compiled by the JSME Research and Recommendation Committee on the Great East Japan Earthquake Disaster (chair: Professor Masaki Shiratori of Yokohama National University) in the Mechanical Engineering Volume of a committee report as well as the recommendations made by Working Group 5 of the committee regarding damage to energy infrastructure. The former recommendations are divided into the following categories: large-scale system integration; approach to design basis and beyond design basis; challenges in risk communication; and continuous investigation and development of codes and standards. Working Group 5 has produced ten recommendations, such as addressing the technical challenges encountered at nuclear facilities and creating a future energy society.
\end{abstract}

KEYWORDS: Great East Japan Earthquake Disaster Report, proposal, mechanical engineering, large-scale system integration technology, beyond design basis, risk communication

\section{Introduction}

The Great East Japan earthquake and tsunami that were generated off the Pacific coast of Tohoku on March 11, 2011, caused what is now referred to as the Great East Japan Earthquake Disaster. The entire eastern half of Japan was affected by the disaster, leaving many people dead or missing. It even triggered an accident at a nuclear power plant. It is no exaggeration to say that the disaster was on an unprecedented scale that had never been seen before in the recorded history of Japan. In the immediate aftermath of the earthquake, the Japan Society of Mechanical Engineers (JSME) set up a taskforce under the leadership of Professor Yoichiro Matsumoto, the 88th president of the society. The taskforce was composed of the Research and Recommendation Committee on the Great East Japan Earthquake Disaster, which was chaired by Professor Masaki Shiratori of Yokohama National University, and another Committee on the Recommendations from a Long-term Perspective, which was chaired by Professor Shigehiko Kaneko of the University of Tokyo. These committees mainly investigated

DOI : $10.15669 /$ fukushimainsights.Vol.3.157

(C) 2021 Atomic Energy Society of Japan. All rights reserved.

Originally published in Journal of the Atomic Energy Society of Japan (ISSN 1882-2606), Vol. 57, No. 10, p. 662-666 (2015)

in Japanese. (Japanese version accepted: July 2, 2015) 
the damage left in the wake of the disaster from the viewpoint of mechanical engineering. With the aim of creating a more robust society, they also examined matters that engineers and researchers in the field of mechanical engineering need to reflect on, lessons that they should learn, areas that will need to be improved in the future, and positive roles that the JSME can play. The Research and Recommendation Committee on the Great East Japan Earthquake Disaster involved as a part of eight academic societies in its joint investigation. These societies were the Japanese Geotechnical Society, the Japan Society of Civil Engineers, JSME, the Architectural Institute of Japan, the Atomic Energy Society of Japan, the Seismological Society of Japan, the Japan Association for Earthquake Engineering, and the City Planning Institute of Japan. The outcomes have been compiled in the Report on the Great East Japan Earthquake Disaster-Mechanical Engineering Volume ${ }^{1)}$. Yasuo Koizumi, the author of this commentary, participated in these investigations as a committee member and the chair of one of the eight working groups formed under the committee (Working Group 5 on damage to energy infrastructure). This commentary discusses the recommendations compiled in the report and other recommendations made by Working Group 5.

\section{Recommendations Made by the JSME Research and Recommendation Committee on the Great East Japan Earthquake Disaster}

\section{Committee Structure and Activities}

Consisting of ten members (including the author) and four observers, the research committee chaired by Professor Shiratori established the following eight working groups.

Working Group 0: Characteristics of the Earthquake and Tsunami—chaired by Kojiro Irikura (Aichi Institute of Technology)

Working Group 1: Damage to Machines and Equipment and Good Practices for Seismic Countermeasures—chaired by Professor Satoshi Fujita (Tokyo Denki University)

Working Group 2: Understanding the Mechanism of Tsunami-induced Damage to Machines and Structures Based on Mechanical Analysis_chaired by Professor Shinobu Yoshimura (University of Tokyo)

Working Group 3: Challenge of Robot Technologies at the Disaster Sites—chaired by Professor Hisashi Ohsumi (Chuo University)

Working Group 4: Analysis of Traffic and Physical Distribution Systems in Areas Affected by the Disaster-chaired by Professor Takayoshi Kamada (Tokyo University of Agriculture and Technology)

Working Group 5: Damage to Energy Infrastructure—chaired by Yasuo Koizumi (Shinshu University)

Working Group 6: Nuclear Codes and Standards and Future Perspective-chaired by Professor Masaki Morishita (Japan Atomic Energy Agency)

Working Group 7: Crisis Management in Earthquakes, Nuclear Accidents, and Other Events—chaired by Keiji Kondo (Fukuda \& Kondo Law Office)

The various investigations were conducted by the respective working groups over the 
course of two years with the aim of, for instance, assessing the damage, considering scenarios for reconstruction, and ensuring better preparedness for crisis management. Rather than being fixated on the extent of damage, these investigations adopted basic principles aimed at proactively identifying good practices for crisis management that would mitigate damage. Issues related to nuclear power plants and other such matters were carefully divided into categories. In addition, the various types of damage were sorted according to whether they were caused by seismic forces or the tsunami.

Reports and recommendations from the respective working groups were, after due peer review and coordination, compiled in the Report on the Great East Japan Earthquake DisasterMechanical Engineering Volume.

\section{Recommendations for Mechanical Engineering Based on Lessons Learned from the Last Earthquake-Induced Disaster}

The damage wrought by the disaster was so enormous and extensive that it needed to be covered in a wide range of reports. The committee considered what types of recommendations should be presented to society as well as what lessons engineers and researchers of mechanical engineering should learn from the disaster. As chair of the committee, Prof. Shiratori led the process of extracting recommendations from a broad range of perspectives.

The findings were summarized in "Recommendations for Mechanical Engineering Based on Lessons Learned from the Great East Japan Earthquake" as follows:

(1) Large-scale system integration

(2) Approach to design basis and beyond design basis

(3) Challenges in risk communication

(4) Continuous investigations and development of codes and standards

\section{(1) Large-scale system integration}

A large-scale system for a nuclear power facility or the like integrates knowledge from a wide range of science and engineering fields to constitute the system. However, this system has proven to be beset by vulnerabilities associated with gaps among the various different types of expertise when it is exposed to an earthquake, a tsunami, or another major disaster. These vulnerabilities must be addressed by establishing a methodology for system integration to examine the overall picture of the system, identify the weak spots hidden within the gaps among the various different types of expertise, and implement the necessary measures. The JSME also recommends its own society-wide initiatives in an effort to systematize a "science of design."

Researchers who engage in cutting-edge research at universities and the like tend to be interested in the "science of recognition" within their narrowly segmented fields. They have neglected efforts to systematize a "science of design" aimed at integrating the knowledge that they obtain from their research. The outcomes obtained from cutting-edge research in a science of recognition are supposed to be incorporated into patents, codes, and standards for practical application in society. In reality, however, the researchers seem to be content with just publishing their papers.

System integration is commonly conducted at a company's manufacturing sites to accumulate empirical knowledge in relation to design, manufacturing, operations, and so forth. Although sufficient information can be accumulated with respect to cars, electronic devices, and 
other mass-produced products, it is an unfortunate fact that little integration has taken place with respect to nuclear power generation, the space industry, and the development of other large-scale systems employed in society.

System integration is required from the moment a project is launched to develop a largescale system. A team of experts from various fields is assembled to conduct the necessary integration on various levels, from the individual level through to the global level.

\section{(2) Approach to design basis and beyond design basis}

An artificial object can be designed only after the required specifications, including the maximum external force that the intended object is expected to endure over its service life, have been determined. If an external force from an earthquake, tsunami, or other major natural disaster may exceed this postulated limit, the following two questions need to be addressed.

(1) How should the postulated limit (safety goal) be determined?

(2) How should an event exceeding the postulated limit (i.e., beyond design basis) be dealt with?

The last earthquake disaster taught us the need to provide explanations for any safety goals that form the basis for a postulated limit and the risks of emergencies that may exceed this limit to ensure that society regards the risks as acceptable. Such a procedure is recommended for any postulated limit, and it should be applied not only to nuclear facilities, but also to chemical plants, railway systems, and other large-scale systems.

A postulated limit is commonly called a design basis. Any such value that involves safety is also called a safety goal. Postulated limits used to be determined based on discussions held by advisory boards of experts. However, these experts failed to help the public gain a clear understanding of their complicated and technical discussions. Prior to the assignment of any postulated limit, explanations must be provided regarding the safety goals that form its basis and the risks of emergencies that may exceed this limit to ensure that society regards the risks as acceptable.

Such a procedure should be taken not only with nuclear facilities, but also with chemical plants, railway systems, and other large-scale systems.

It is also important to obtain public consensus on the definition of damage that exceeds the socially acceptable limit, and this should be accompanied by discussions and preparations regarding the technical means required to support the necessary measures. The last earthquakeinduced disaster revealed not only a failure to give due consideration to the possibility that damage to a nuclear power plant may exceed the socially acceptable limit, but also a failure to implement the necessary measures. Artificial objects usually carry risks, and proper management of residual risks is required. The principle of zero disasters is not viable.

With respect to mechanical safety education, Umezaki ${ }^{2)}$ points out the following: "In Japan, a reduction in the incidence of industrial accidents is typically sought by enhancing the reliability of machines and improving education and training for workers. By nature, however, people make mistakes and machines experience failures and other such problems. Measures must be taken based on the assumption that these problems do take place. To this end, foolproof and fail-safe designs as well as other safety technologies have an essential role to play." Umezaki goes on to say, "Safety in Japan has been pursued by adopting measures based on the principle of zero disasters with no tolerance for industrial accidents. In contrast, the West 
has advanced the concept of risks by conceding that absolute safety cannot be achieved. Rather than insisting on the supposed notion of zero disasters by assuming no risks, it seems more important to clarify residual risks, provide users with the appropriate information, and clarify measures for managing residual risks (e.g., building safety management systems, establishing work procedures, conducting education and training, and using protective gear)." This reasoning embodies the approach associated with design basis and beyond design basis.

\section{(3) Challenges in risk communication}

In the design phase for any artificial object, the engineers and researchers involved in its manufacture need to predict the expected benefits and associated risks accurately, communicate them to the public, and obtain public acceptance. To do this, they must acquire two types of skills: the ability to accurately predict and manage risks (risk management) and the ability to communicate risks accurately to obtain public acceptance (risk communication). These qualities are expected of not only the individual engineers and researchers, but also the relevant universities, companies, governments, and other organizations. It is also recommended that the JSME earnestly engages in risk communication/management, and build and implement a system for delivering the necessary information to the public in a timely fashion to obtain public understanding.

With science and technologies advancing into ever more extensive areas, it has become almost impossible for the public to understand them accurately. People accept the black box of science and technologies to enjoy the benefits that they offer. Nonetheless, there are postulated limits and safety goals for each artificial object. It is quite difficult to explain this fact to the public and obtain their understanding. For this reason, the public tends to lose trust in engineers and researchers whenever trouble arises.

Experts need to obtain public understanding by providing the public with scientifically supported information. This task is needed to allow citizens to make the right choices regarding the possible resumption of nuclear power and future energy sources.

People expect both guaranteed safety and use at ease at all times. However, these two things do not go hand in hand. It needs to be clearly explained that there are always postulated values and limits to safety and that the possibilities of accidents that exceed these limits can never be excluded. The public must be properly informed of the safety limits (risks) of artificial objects as well as their benefits. To this end, the following two skills need to be acquired.

1. The ability to accurately predict and manage risks (risk management)

2. The ability to communicate risks accurately to obtain public acceptance (risk communication)

The methodologies used for risk management include probabilistic risk assessments.

Science communication skills must be acquired to ensure proper risk communication on engineering issues. The JSME and other expert groups should communicate their opinions on any new technical challenges that may have social repercussions after reaching agreement through careful discussions. 
(4) Continuous investigations and development of codes and standards

The JSME will reinforce its partnership with the industrial and academic communities to apply the lessons learned from the Great East Japan Earthquake Disaster and mitigate the impact of any future massive earthquakes or other such disasters. Through this partnership, the findings from investigation and other research will be compiled to produce codes, standards, manuals, and so forth. The recommendations made by each of the working groups should be implemented with sincerity. To pass on the lessons learned from the last earthquake-induced disaster, the JSME also recommends human resource development, education, and training for junior researchers and engineers.

The more society matures, the more its citizens must shift their mindsets to engage more proactively in the process used to establish the codes and standards that concern them. Since the Meiji Restoration, the Japanese government has led the application of the codes and standards that they have established. For this reason, people today still expect someone else to prepare the codes and standards, and they feel content to follow the rules established by others. Such a mindset must be cast aside. An environment that is conducive for industry stakeholders to participate proactively in the process of creating codes and standards should be prepared so that they can give back what they output. Such an environment will also cultivate fertile ground for public trust in technologies.

\section{Recommendations Made by Working Group 5 on Damage to Energy Infrastructure}

\section{Activities by Working Group 5}

Working Group 5 has already published an interim report on their activities ${ }^{3)}$. This commentary mainly presents the recommendations that were compiled thereafter.

The Pacific coast of Japan, which stretches from the Kanto region to the Tohoku region, is a major source of power that is generated by many thermal and nuclear power plants. Regardless of their type, these power plants were severely affected by the 2011 Great East Japan earthquake and tsunami. However, studies have revealed the robustness of thermal power plants and the vulnerability of nuclear power plants. Damaged thermal power plants were swiftly repaired to resume power transmission, so power shortages lasted much less time than was initially feared. Even the Haramachi Thermal Power Plant resumed its supply of power just one year and eight months after being devastated during the disaster.

Today's thermal power generation draws from the improvements that James Watt made to steam engines and the subsequent advancements in the technology to convert heat into mechanical energy. Initially, steam engines relied on a vacuum. Following the natural course of events, however, greater efficiency was pursued by using high-pressure engines despite strong resistance from James Watt. Larger boilers that made use of increasing amounts of pressure took a heavy toll, though. In around 1900, the United States recorded 300 to 400 boiler explosion accidents a year that resulted in up to about 10,000 injuries and about 1,000 deaths. To address this problem, the American Society of Mechanical Engineers created the Boiler \& Pressure Vessel Code. The introduction of third-party inspections significantly reduced the incidence of boiler explosion accidents. This means, then, that thermal power technology took 
200 years to mature and achieve its current level of robustness.

Commercial nuclear power generation began in Japan only about 50 years ago. Given this, it is safe to say that this technology still needs to mature over a much longer timeframe. It is, of course, extremely unfortunate that many people have been affected by accidents at nuclear power plants. Nevertheless, if we view this from the perspective of the history of technical advancements, nuclear power generation technology seems to have matured considerably over this short amount of time. This progress may have caused harm and people tend to focus on the vulnerability of nuclear power technology, but technical advancements take time and unfortunate events may happen along the way. However, technical maturity should also be sought by learning from such experiences. All of the members of Working Group 5 were united in their pursuit of a more robust and safe technology through necessary improvements, development activities, and countermeasures by heeding the lessons learned from the last disaster.

Historically speaking, the Japanese archipelago has been hit by massive earthquakes and tsunamis on a regular basis. Despite this, the Japanese people have built a nation on these islands, which are now home to almost 120 million people, including over 10 million people living in a single megacity. Unfortunately, memories of these natural disasters cannot be easily perpetuated as they strike Japan every few generations. Their national traits did not help either. In relation to education and training too, all of the members of Working Group 5 perceived the need to ensure physical and mental preparedness by leaving records, passing on stories, and regularly remembering the disasters of the past.

\section{Recommendations Made by Working Group 5}

Against this background, Working Group 5 has developed recommendations on the following ten issues.

(a) Technical issues at nuclear facilities

(b) Operational issues at nuclear facilities

(c) Social responsibilities of engineers, managers, and governments with respect to nuclear facilities

(d) Issues involving thermal power plants

(e) Lessons learned from the Great Hanshin Earthquake of 1995 that can be applied for energy systems

(f) Importance of preparedness through mitigative measures taken with energy systems

(g) Need for diversified energy sources

(h) Important perspectives for discussing energy policies

(i) Social impact of structural shifts in energy supplies and roles of engineers

(j) Building a future energy society

Due to space limitations, explanations will be provided for only some of these issues, not all of them. For more details, please refer to reference material ${ }^{1)}$.

\section{(1) Technical issues at nuclear facilities}

Important lessons can be drawn from the construction work that was carried out back then to raise the height of the protection wall (by between $1.6 \mathrm{~m}$ and $2.8 \mathrm{~m}$ ) for the seawater pumps at the Tokai No. 2 Nuclear Power Plant. The motors of the seawater pumps for cooling the emergency diesel generators avoided flooding by the tsunami in the part of the levee where holes had already been covered, but the motors of the other cooling seawater pumps were flooded in the part where holes had not been covered. Furthermore, gas turbines located on 
the roof of the important quakeproof building proved effective in supplying emergency power. These experiences suggest that sensible safety measures can technically deal well with flooding from a tsunami.

(2) Social responsibilities of engineers, managers, and governments with respect to nuclear facilities

Engineers and managers involved in electric power generation bear a social responsibility to modify the systems and operational methods for providing a vast amount of energy while always paying attention to state-of-the-art technologies. It is essential to recruit personnel who can make judgments based on the overall perspective and to organize practical education and training programs to build up this capacity among personnel on a steady basis.

(3) Lessons learned from the Great Hanshin Earthquake of 1995 that can be applied for energy systems

The Great Hanshin Earthquake of 1995, which struck directly beneath a metropolitan area, prompted a revision of Japan's technical standards. Despite the extensive damage that was caused across East Japan by the 2011 Great East Japan earthquake, which had a magnitude of 9.0, the proportion of transmission and substation facilities that suffered damage was definitely less than that from the Great Hanshin Earthquake. This achievement demonstrates how important it is to dutifully apply the lessons of the past and implement the necessary measures.

\section{(4) Need for diversified energy sources}

Unfortunately, as a land that is prone to natural disasters, Japan must secure energy sources for both regular use and emergency use. Electric power is one of the most important utilities, and the last tsunami taught us the importance of building up port facilities that can supply power from vessels to land as well as the development of onshore facilities with standalone power generators. In addition to disaster management, due consideration should be given to securing fuel supply chains and storage as well as easing the relevant regulations and implementing the necessary ordinances in places. One example of this is the easing of restrictions under the Fire Service Act on the storage capacity for fuels used to generate power at core evacuation facilities in areas affected by disasters. Indeed, the recovery of the gas supply in Sendai in just one month owes greatly to the main gas pipeline from Niigata to Sendai. Such infrastructure should be put in place throughout Japan.

(5) Social impact of structural shifts in energy supplies and roles of engineers

A hasty all-out transition from nuclear energy to thermal power and renewable energy sources would probably have many serious consequences for future Japan. Rising fuel costs would push up power generation costs. Furthermore, the production capacity of Japanese companies might be depressed by power shortages, which could further speed up the offshoring of their operations. People would find it harder to live with fewer employment opportunities and lower incomes, and it would be harder to fulfill the country's commitments to curbing global warming. In addition, Japan would not be able to make any technical contributions to emerging economies that need nuclear energy. In fact, the international community could cease to trust Japan on nuclear non-proliferation and other issues. Learned societies have an important mission to communicate these scientifically grounded arguments clearly to the public. The media and other entrusted organizations must understand their social role in communicating risk to the public and their responsibility to disclose accurate information and serve as a bridge between engineers and the public.

(6) Building a future energy society 
The method that Japan uses to source its electric power will have a significant impact on the future of this resource-scarce country, how its people live, and how its society will function. Sources of electric power should be determined after long, hard discussions have been conducted based on scientific findings and evidence. This decision must be unswayed by simple cost estimates and emotional arguments. These discussions should be made from multifaceted perspectives to address intricately intertwined issues (e.g., long-term energy security as well as the possible impact on industry, the economy, employment, society, people's lifestyles, and the fight against global warming). An optimal mixture of energy sources should be sought by clarifying the characteristics of nuclear, thermal, and other existing power generation systems and by properly promoting renewable energy. To this end, consideration must be given to both people's lifestyles and industrial growth while duly ensuring the safety of nuclear energy.

\section{Conclusions}

This commentary mainly presents the recommendations compiled by the JSME Research and Recommendation Committee on the Great East Japan Earthquake Disaster (chair: Professor Masaki Shiratori of Yokohama National University) in the Mechanical Engineering Volume of the Report on the Great East Japan Earthquake Disaster as well as the recommendations made by Working Group 5 of the committee regarding damage to energy infrastructure. Japan is hit by massive earthquakes, tsunamis, and other natural disasters on a regular basis. Such experiences could not be passed on very easily, because they strike Japan every few generations. I hope that lessons will be drawn from the damage caused by the last earthquake-induced disaster, passed on to the next generation, and applied in practice to create a more robust society built on technologies.

\section{References}

1) Joint Editorial Committee for the Report on the Great East Japan Earthquake Disaster: Report on the Great East Japan Earthquake Disaster-Mechanical Engineering Volume [in Japanese], Maruzen, 2013.

2) Shigeo Umezaki: Mechanical Safety Training for Mechanical Design Engineers [in Japanese], Journal of Japan Boiler Association, Vol. 389, 2015, 4-10.

3) Yasuo Koizumi, Hitoshi Asano, and Tomio Okawa: Introduction of the Activity of the WG5 Damages of Energy Infrastructure in the Research Committee for the Urgent Surveys of the East Japan GreatEarthquake and Proposals of Future Measures of the Japan Society of Mechanical Engineers [in Japanese], Journal of the Atomic Energy Society of Japan, Vol. 54, No. 12, 2012, 789-793. 